\title{
Diet selection by steers on a natural pasture in Vicosa, Brazil
}

\author{
D Nascimento Jr 1, LJ Torregroza 2, JMS Diogo 1 \\ 'Federal University of Vicosa, Department of Zootecnia, Vicosa, Brazil ; CIAT, Calle, Colombia
}

The objective of the present study was to evaluate diet selection of the animals on a natural pasture during the dry and wet seasons. The area of the study was approximately 8 hectares with a rough topography, presenting a sequence of concave-convex segments as described by Rezende (1971, Thesis, Univ Vicosa, 71 p). The physical-chemical characteristics and herbaceous structure were described by Pimentel et al (1982, Rev Soc Bras Zoot, 11, 168-187), Diogo et al (1988, Rev Soc Bras Zoot, 17, 578-585), Pacheco et al (1987, Rev Soc Bras Zoot, 16, 337-351), Coser et al (1989, Rev Soc Bras Zoot, 18, 48-53), and Torregroza et al (1993, Rev Soc Bras Zoot, 22, 839-851). Samples were collected for five consecutive days in the second week of the months of December 1990, January and February 1991 which correspond to the rainy season, and then in the second week of June, July, and August 1991 which correspond to the dry season. Samples of the diet were obtained utilizing four esophageal-fistulated animals. One day each month, when samples were taken of the forage consumed, samples were taken of the forage in the pasture to determine the botanical composition of the forage available in the pasture. The production of dry matter by the pasture was estimated by the comparative yield method (Haydock and Shaw, 1975, Austr J Exp Agric Anim Husb, 15, 663670 ), and the botanical composition by the dryweight method (Mannetje and Haydock, 1963,
J Brit Grassl Soc, 18, 268-275). The data were processed by the computer program, Botanal. Botanical composition was estimated by the microscopic point method (Heady and Torell, 1959, J Range Manag, 12, 28-33). The botanical composition of the forage available and that in the diet were compared. The animals showed a preference for grasses with molassesgrass (Melinis minutiflora, Pal de Beauv) being the main species in the diet representing $45 \%$ of the total during the rainy season and $37.3 \%$ in the dry season.

Jaraguagrass (Hyparrhenia rufa, (Ness) Stapf) was highly selected during the rainy season, representing an average of $24.7 \%$ of the total. Molassesgrass was the major species in the diet of the animals, not only in the rainy season, but also in the dry season. The high rate of selection of Jaraguagrass during the rainy season was in contrast to a high rate of rejection during the dry season. Batataisgrass (Paspalum notatum Flugge) was preferred by animals when it was in the regrowth stage or in an advanced stage during the dry season. The smaller proportion of "the other grasses" in the diet characterizes rejection of these by the animals. The animals rejected the leguminous plants (Pueraria spp, Crotalaria spp, Stylosanthes spp) and the "weeds and brush" (Bidens pilosa $L$., Ageratum conizoides L., etc.) in the rainy season. Nevertheless, the high selection of these species in the dry season showed the ability of these species to prolong the pasture season and to improve the quality of the diet. 